\title{
A CONSTITUIÇÃO DE CUBA E QUESTÃO AGRÁRIA ${ }^{12}$
}

\section{THE CONSTITUTION OF CUBA AND THE AGRARIAN ISSUE}

\author{
Anne Geraldi Pimentel ${ }^{3}$ \\ Carlos Frederico Marés de Souza Filho ${ }^{4}$
}

\begin{abstract}
Resumo: Com a recente Reforma Constitucional em Cuba surgiu a necessidade de analisar as continuidades ou descontinuidades do processo de formação do Estado dentro dos ideais socialistas. Assim, este artigo teve como objetivo verificar alguns pontos que indicam a continuidade dos ideais socialistas presentes ao Estado cubano desde a Revolução de 1959. Uma destas continuidades se revela na forma como vem sendo tratada a questão agrária no país, isto porque a reforma agrária foi uma das primeiras medidas do governo pós 1959 e um dos pilares da formação do Estado. A questão agrária remete imediatamente à questão constitucional do uso e propriedade da terra, que foi reescrito na nova Constituição cubana. A nova forma de tratamento à propriedade da terra manteve os ideais de 1959. O método de investigação escolhido foi o qualitativo, isto se deve à complexidade do objeto, que deverá constar de análises das estruturas sociais para compreender os fenômenos. Os procedimentos metodológicos elegidos foram pesquisa bibliográfica, documental e depoimentos.
\end{abstract}

Palavra-chaves: Cuba; Questão Agrária; Reforma Constitucional; Estado Socialista; Direito Constitucional.

\begin{abstract}
The recent Constitutional Reform in Cuba has given rise to the need to analyze the continuities or discontinuities of the state formation process within socialist ideals. Thus, this article aimed to verify some points that indicate the continuity of the socialist ideals present to the Cuban state since the Revolution of 1959. One of these continuities reveals in the way the agrarian question in the country has been treated, because the agrarian reform has been one of the first post-1959 government measures and one of the pillars of state formation. The agrarian question refers to the constitutional issue of land use and ownership, which was rewritten in the new Cuban Constitution. The new form of treatment of land ownership maintained the ideals of 1959. The method of investigation chosen was the qualitative one, due to the complexity of the object, which should consist of analyzes of social structures to

\footnotetext{
${ }^{1}$ Artigo recebido em 29 de julho de 2019 e aprovado em 29 de outubro de 2019.

${ }^{2} \mathrm{O}$ presente trabalho foi realizado com apoio da Coordenação de Aperfeiçoamento de Pessoal de Nível Superior - Brasil (CAPES) - Código de Financiamento 001.

${ }^{3}$ Doutoranda em Direito pelo Programa de Pós-Graduação da Pontifícia Universidade Católica - PR, linha de pesquisa em Direito Socioambiental e Sustentabilidade. Grupos de estudos: Meio Ambiente: Sociedades Tradicionais e Sociedade Hegemônica PUC/PR e Coletivo de Estudos e Ações em Resistências Territoriais no Campo e na Cidade - CERESTA. Bolsista CAPES, Programa de Doutorado Sanduíche no Exterior - PDSE, processo $\mathrm{n}^{\mathrm{o}}$ 88881.188031/2018-01. Correio eletrônico: hannah_agp@yahoo.com.br. ORCID: https://orcid.org/0000-0002-3774-2425.

${ }^{4}$ Professor Doutor titular da PUC- PR, vinculado ao Programa de Pós-Graduação em Direito. Grupos de estudos: Meio Ambiente: Sociedades Tradicionais e Sociedade Hegemônica PUC/PR. Correio eletrônico: carlosmares@terra.com.br. ORCID: https://orcid.org/0000-0001-6529-6058.
} 
understand the phenomena. The methodological procedures chosen were bibliographic research, documentary and testimonials.

Keywords: Cuba; Agrarian Question; Constitutional Reform; Socialist State; Constitutional law.

\section{Introdução}

"Tierra o sangre"

Realengo 18

Cuba promulgou uma nova constituição em abril de 2019 depois de um processo de discussão que durou mais de um ano, a constituição cubana vigente era de 1976. Cuba foi o último país a se tornar independente do colonialismo Europeu no século XIX e seu herói, José Martí, é um dos mais prolíferos entre os libertadores, enquanto os outros foram econômicos nos escritos, ele tem uma vasta obra e de caráter claramente anticolonial.

Historicamente a Revolução Socialista é filha direta das lutas pela independência, com uma distância de apenas 60 anos, contando o fim de cada uma delas, a primeira em 1898 e a segunda em 1959 (GUERRA VILABOY, 2012). Isso significa que no início das hostilidades revolucionárias do século XX, em 26 de julho de 1953, quando os revolucionários tentaram tomar o quartel de Moncada $^{5}$, toda a população com mais de 55 anos tinha vivido sob o domínio espanhol. O império somente aboliu a escravidão em Cuba dois anos antes do Brasil, em 1886, portanto durante o processo de independência. Também é fato conhecido que a Espanha tentou vender Cuba para os Estados Unidos e só não conseguiu porque o povo cubano impediu (GUERRA VILABOY, 2012). A ilha sofreu um massacre indígena genocida, relatado desde o começo do século XVI por Bartolomé de Las Casas (CASAS, 1985), passando a ter uma forte ascendência africana, devido ao tráfico dos povos da África para atender aos interesses coloniais de produzir mão-de-obra escrava.

A ilha colonial foi sempre produtora e exportadora de produtos agrícolas, açúcar e tabaco, principalmente. Continuou assim depois da independência porque as elites locais mantiveram uma colonialidade servil em relação aos Estados Unidos. Daí, que desde as guerras de independência, no final do século XVIII, havia uma insatisfação entre os camponeses contra a forma de propriedade e ocupação da terra e a própria produção agrícola. Cuba, assim, sempre foi um país agrícola. Afinal, houve uma revolução nos anos 50 que

\footnotetext{
5 Esta ação dos revolucionários foi derrotada pelo exército da república fictícia. Ao final, resultou na prisão dos insurgentes, contudo este momento foi bastante importante por dois motivos: foi escrito o Programa de Moncada, no qual Fidel Castro apontou para a necessidade de reforma agrária; e nasceu o movimento revolucionário 26 de julho, cujos membros deram início às lutas pela queda do Ditador Batista e o fim do colonialismo estadunidense (RÍOS HERNÁNDEZ, 2015; FERNANDES, 2012, p. 45).
} 
culminou com o alinhamento socialista. A sociedade cubana, socialista, sofreu, por isso, um impacto profundo com o fim da União Soviética que era seu principal comprador e fornecedor de produtos. Cuba sofre um embargo econômico desde os anos 60, portanto, qualquer comércio exterior é difícil, isso impede que Cuba e os cubanos acessem novos produtos da tecnologia, incluindo remédios, alimentos e eletrônicos. No período da Guerra Fria esse embargo era contornável pelo comércio com a URSS que comprava praticamente todo o açúcar produzido e vendia todas as necessidades, inclusive de alimentos processados. Com o fim da URSS, se imaginou que seria o fim de Cuba socialista e seu governo. De fato a crise era sem precedentes para Cuba revolucionária, aumentando o índice de mortalidade infantil que já era igual a dos países mais desenvolvidos, e o de desemprego chegou a $6 \%$, inadmissível para uma economia planificada. Era a crise.

Cuba, então, entrou num processo de renovação e busca de novas alternativas econômicas entre as quais a produção de alimentos, tendo que reestruturar não só a forma de produção, mas também o acesso à terra e o incentivo aos camponeses. Mais uma vez os camponeses assumiriam um papel preponderante na história da ilha. Nesse processo de busca de alternativas, muitas coisas tiveram que ser alteradas, incluindo o fechamento do país aos estrangeiros, sejam investidores ou turistas, inclusive uma das alternativas de sobrevivência encontrada foi a abertura do setor de turismo. Estas mudanças eram sempre discutidas amplamente com a população pelas estruturas políticas montadas pela Constituição de 1976, até que, em 2017 amadureceu a ideia de promover uma reforma constitucional para absorver o que vinha ocorrendo desde o fim da URSS, em 1991 e porque as novas políticas agrárias haviam dado resultados positivos, acabado com o espectro da fome, principalmente.

A Reforma Constitucional em Cuba oferece uma oportunidade de se analisar as continuidades e descontinuidades do processo de construção do Estado socialista. Mas a questão agrária aparece como essencial e um dos pilares da formação do conceito do Estado socialista cubano, porque a ação dos camponeses na luta pela terra e manutenção de sua própria sobrevivência, foi fundamental no processo, desde a independência. Por isso a escolha para tratar desta questão agrária na reforma constitucional de 2018-2019. Assim, este artigo tem como objetivo verificar alguns pontos que indicam a continuidade e avanço dos ideais socialistas desde a Revolução de 1959 e expressos na nova constituição. Para isso, compreendemos que é importante resgatar todo o processo de luta por independência, desde o século XIX, cujo objetivo foi justamente a construção do Estado moderno cubano, que é a própria luta pela soberania sobre o seu território, o que por si só já é a questão agrária. 
O método de investigação escolhido foi o qualitativo, isto se deve à complexidade do objeto $^{6}$. Os procedimentos metodológicos elegidos foram pesquisa bibliográfica, documental e depoimentos. Para a construção da parte teórica foi realizado um levantamento bibliográfico que se constituiu de livros, artigos, teses que se refiram ao tema a ser investigado, bem como documentos como leis, decretos, normativas, aos quais foram dados os tratamentos de catalogação e referenciadas para dar suporte à construção do referencial teórico. Também deu suporte ao referencial teórico o depoimento da advogada e professora Yarina Amoroso Fernández da Universidad de las Ciencias Informáticas (UCI) e membro da União Nacional de Juristas Cubanos (UNJC).

\section{Da formação do Estado moderno à reforma constitucional 2018-2019}

O Estado moderno nasceu sob a égide da unidade territorial e do poder soberano exercido pelo povo que estabelece um governo que o pratica. Isto, está claro, não se deu sem muita disputa, guerras e tentativas realizadas e frustradas de anexações em diversos momentos na Europa. Portanto a construção dos Estados Modernos Europeus não foi nem pacífica nem harmônica sendo estabelecida, sempre, a partir da correlação de forças do momento. Se assim foi na Europa, mais intensa e difícil tem sido a construção dos Estados Nacionais Americanos, cujo processo se iniciou no fim do século XVIII, com os Estados Unidos da América e o Haiti.

A constituição dos Estados Nacionais Latino-americanos passaram por lutas muito características porque ao mesmo tempo em que encetava uma luta contra a Metrópole Colonial, que por si só já era uma guerra de grande monta, havia distorções internas que nem todos queriam resolver, como a garantia de territorialidade aos povos indígenas e a libertação dos escravos. A maior parte dos Estados Nacionais Latino-americanos, depois de conseguir derrotar as forças coloniais negou direito de liberdade aos escravos e aceitou uma nova forma de colonialidade e os governos retiraram direitos soberanos aos povos e submeteram a vida nacional a uma economia dependente.

O caso de Cuba ganha um relevo ainda mais específico por ter sido o último país a se tornar independente na América no século XIX, com uma guerra de independência que foi sendo feita com grandes contradições internas e muita influência externa, especialmente dos

\footnotetext{
${ }^{6}$ Para Richardson (1985, p. 39), a escolha do método qualitativo se deve às características do objeto, assim, "podemos afirmar que, em geral, as investigações que se voltam para a análise qualitativa têm como objeto situações complexas ou estritamente particulares".
} 
Estados Unidos da América cuja proximidade é alarmante. A tradição insurrecional, principalmente camponesa, se fez sentir já no início das lutas de independência como estabelecimento de grupos armados, chamados mambises, que em abril de 1869 aprovaram uma constituição criando a República de Cuba. Diferente da maior parte das primeiras Constituições do continente, esta aboliu a escravatura e teve grande adesão dos trabalhadores, embora o texto constitucional fosse ainda muito marcado pela tradição europeia (GUERRA VILABOY, 2012, p. 23). Apesar da Constituição, a guerra continuou.

Em 1877 foi assinado um tratado de paz sem independência. Cuba continuaria uma colônia. Quase vinte anos depois, já com proposta estruturada da formação do novo país, estalou a nova revolução, agora liderada pelo jornalista e escritor José Martí, criador do Partido Revolucionário de Cuba e artífice do programa da revolução. Martí seria morto no primeiro ano, mas seu ideário de soberania e independência continuaria germinando por muito tempo (MARTÍ, 1971). Assim, um dos elementos mais importantes para se compreender a trajetória de Cuba é a soberania, foi por ela que o povo cubano lutou duas guerras de independência no século XIX e depois promoveu a revolução da década de 50 do século XX.

Todo este caminho da concepção de soberania foi importante para se pensar política e juridicamente a conformação do conceito na atualidade. Pode-se dizer que politicamente, é um poder constituído pela autodeterminação de um povo como livre e independente, com autogestão na escolha de sua forma de governo, sistema político e econômico, cujo poder estará vinculado a um determinado espaço territorial, não podendo nenhum outro poder externo restringi-lo ou limitá-lo. Juridicamente, também é um poder, como explica Dallari (2011, p. 34), de "decidir em última instância sobre a atributividade das normas, vale dizer, sobre a eficácia do direito", significa que o Estado constrói seu sistema de normas a partir de sua autodeterminação e nenhum poder externo pode influenciar ou determinar como ou o quê a normatividade deve regular.

Neste sentido, Maluf (2006, p. 27) vincula o conceito de soberania à própria organização do governo, sendo este, "o conjunto das funções necessárias à manutenção da ordem jurídica e da administração pública". Assim, o governo como elemento essencial à formação do Estado Moderno, na teoria de Maluf (2006, p. 27), é pressuposto da soberania. E é requisito essencial a independência, portanto este governo deve ser definido de forma independente e autônoma, sem interferência externa, sem isso, será um estado imperfeito ou um semi-estado (MALUF, 2006, p. 33). 
Voltando para o caso da maior das Antilhas do Caribe, a conquista de sua liberdade foi uma guerra que durou 60 anos, desde sua primeira tentativa de conceber um pacto social livre e independente de seu primeiro colonizador, a Espanha, em 1869, com a assembleia constituinte no município de Guáimaro ${ }^{7}$, província de Camaguey, até o triunfo da Revolução em 1959, quando se liberta de seu segundo colonizador, os Estados Unidos da América. Entretanto, são perceptíveis algumas fases neste processo histórico: a primeira que vai de 1869 a 1898, a luta pela libertação de Espanha, cuja relação era explicitamente colonial; e o segundo, de 1898 a 1959, com a dominação dos Estados Unidos da América, período neocolonial, ou de colonialidade com governos títeres formados pela elite local, marcados pela violência contra camponeses e pelo domínio privado da terra.

No sistema colonial, marcado pela dominação direta da Espanha, Cuba era fonte de recursos naturais, importante polo de produção de artigos como tabaco e açúcar, bem como de criação de gado (FERNANDES, 2012, p. 45). Neste período, não havia nenhuma intenção de formação de um Estado Moderno soberano e independente, havia o domínio territorial da coroa espanhola na ilha cubana, onde a última jurisdição administrativa era o rei de Espanha, sendo, então, uma mera extensão do Estado Espanhol (CARRERAS, s.d, p.13).

Mesmo com a vitória contra a Espanha, em 1898, Cuba não conseguiu formar seu Estado moderno, livre e soberano, já que os Estados Unidos começou a intervir diretamente em seu território, determinando suas leis e seu governo, portanto, houve a formação de um semi-estado ou estado imperfeito. Isso ocorre por um poder externo, os EUA, que conseguiram convencer aos parlamentares constituintes a inserir a Emenda Platt na Constituição da República de Cuba do ano 1901, com objetivo de controle econômico e político. Esta emenda era uma lei estadunidense que foi inserida na Constituição de 1901, através da aprovação da assembleia nacional cubana, com mais da metade dos votos. Nela estava previsto não somente a cessão de bases militares em território cubano, mas também o direito dos EUA de intervir com suas forças armadas quando fosse necessário proteger a vida, a propriedade e as liberdades individuais; e, ainda proibia Cuba de firmar tratados ou contrair empréstimos sem o consentimento prévio dos EUA (SOTO PIPPER, 2008, p.8). Por isso que Soto Pipper (2008, p.8) menciona que "la enmienda Platt es una norma que pretende castrar, socavar la soberanía nacional de Cuba y tergiversar el sentido de su autodeterminación”,

\footnotetext{
${ }^{7}$ Esse momento histórico foi de grande importância na formação dos ideais políticos do povo cubano, como menciona Leal Spengler (1995, p.178), "La asamblea constituyente de Guáimaro significó um paso importante em la historia del desarrollo de nuestras ideas políticas; como hecho jurídico sentó las bases sobre las cuales se apoyarían las otras cartas constitucionales de Cuba insurgente".
} 
dessa maneira EUA manteve o controle político e econômico sobre a ilha. Além disso, a eleição de um presidente servil aos interesses estadunidenses, Tomás Estrada Palma, que inclusive renunciou à sua cidadania norte-americana para adequar-se às normas da Constituição de 1901, e depois dele, muitos outros que vieram para cumprir os interesses do país colonizador, até a chegada do ditador Fulgêncio Batista, claro que foi um período extremamente conflituoso de 1901 a 1959, como relata Suaréz (2013, p.55). Para Fernandes (2012), nesta época, houve a formação de um Estado títere, ou República Mediatizada (SUARÉZ, 2013), ou República Fictícia (LEAL SPENCER, 1995, p. 240), devido à interferência político-jurídico dos $\mathrm{EUA}^{8}$, que impediu a formação de um Estado Moderno livre, soberano e independente.

O sistema neocolonial trouxe um período de grande desenvolvimento econômico, "uma época de ouro", como diz Fernandes (2012, p. 76), mas que avançava de modo dependente. Um país agrícola, baseado na monocultura da cana-de-açúcar e que a vendia para seu único comprador, os EUA. Neste contexto de neocolonialismo, os EUA souberam eliminar ou limitar as produções agrícolas cubanas que competiam com seu mercado (RÍOS HERNÁNDEZ, 2015, p. 96) e tornar a economia cada vez mais dependente da produção de açúcar, que não era produzido pelos EUA, e sendo seu único comprador. Contudo, Cuba se tornou uma forma de ampliação do mercado estadunidense, que através dos Tratados de Reciprocidade, mantinham atrelados a venda dos produtos produzidos por Cuba, principalmente o açúcar, e a compra de artigos produzidos pelos EUA (RÍOS HERNÁNDEZ, 2015, p. 100). Entretanto, esse desenvolvimento foi com base nas desigualdades sociais, exploração e expropriação próprias do sistema capitalista de produção. Uma sociedade cindida em classes antagônicas, com a concentração de renda e grandes latifúndios, que aos poucos seriam comprados por capitalistas estadunidenses. Por outro lado, uma classe trabalhadora expropriada e explorada, levada à miséria e a fome ${ }^{9}$.

Esta nova ordem neocolonial só poderia ser extinta através da organização das forças sociais e da luta contra a dominação estabelecida. Ressaltamos que o período entre 1898 e 1959 foi intenso de conflitos e lutas da classe trabalhadora e, principalmente, dos camponeses contra o poder neocolonial que estava impondo uma condição de miséria a todo o país.

\footnotetext{
${ }^{8}$ Interferência que se tornou ainda mais evidente quando em 1906, com a renúncia de Estrada Palma e amparado pela Emenda Platt, o governo dos EUA estabeleceu um governo provisório, momento que ficou conhecido como a segunda intervenção norte-americana em Cuba (LEAL SPENCER, 1995, p. 238 a 244).

${ }^{9}$ Sobre neocolonialismo e seus efeitos ver em: FERNANDES, Florestan. Da guerrilha ao socialismo: a revolução cubana. $3^{\text {a } e d . ~ S a ̃ o ~ P a u l o: ~ E x p r e s s a ̃ o ~ P o p u l a r, ~ 2012, ~ p . ~} 65$ a 84.
} 
Exemplo disso foi o que ocorreu na comunidade de camponeses Realengo ${ }^{10} 18$, situada na província de Guantánamo, onde o Estado cubano tentou retirar os ocupantes produtores de alimentos para agregar a terra à produção dos grandes proprietários exportadores. Os camponeses, contudo, reagiram e lutaram bravamente para manter suas terras, e em resposta às ameaças de derrama de sangue do coronel Fulgêncio Batista ${ }^{11}$, disseram suas palavras de ordem, "Tierra o Sangre", no ano 1933, para reafirmar a defesa do pedaço de terra de onde tiravam o sustento de sua família. Foi assim que Realengo 18 serviu de exemplo para muitas outras lutas camponesas (RÍOS HERNÁNDEZ, 2015, p. 138). Foram essas lutas e convulsões localizadas que acabaram eclodindo na revolução da década de 1950 , porque em meio às revoltas se constituiu a guerrilha armada com o propósito de disputar o poder, cujo objetivo era de formar uma sociedade com valores de igualdade e justiça social, como afirma Fernandes,

a constituição de uma situação revolucionária, que converteu a guerrilha no meio cubano de chegar ao socialismo; e a guerrilha permitiu, a um tempo, desagregar a capacidade de resistência da tirania burguesa e neutralizar a dominação imperialista dos Estados Unidos (2012, p. 88).

E em $1^{\circ}$ de janeiro de 1959, houve o triunfo da Revolução, momento em que o povo cubano alcançou "el disfrute de su total y absoluta soberanía" (LEAL SPENCER, 1995, p. 240). Isto demonstra que a questão agrária faz parte da formação não só do Estado cubano e seu povo, como da história da construção do socialismo no país. Dá-se início a um novo período de construção do Estado Moderno Cubano, livre e soberano, constituído sobre as bases socialistas específicas. Obviamente, isto enfureceu seu antigo dominador, que perdeu seu território e, como retaliação, impôs um embargo econômico unilateral ${ }^{12}$ que vige até os dias de hoje, com períodos de maior ou menor arrefecimento, além de uma série de ataques violentos, inclusive contra o povo cubano, o que determinou um sofrimento imensurável. Foi, então, em meio à necessidade de sobrevivência, que o Estado cubano passou a alinhar-se politicamente com a União Soviética. A partir desta aliança Cuba, no período de 1959-1989,

${ }^{10}$ Realengo no sistema colonial espanhol significava terras separadas de domínio real não entregues a particulares que serviam como um recuo aos brancos pobres e mulatos livres poderem usar e plantar. O então Estado cubano tentou desalojar esses ocupantes para transferir a terra aos grandes proprietários.

${ }^{11} \mathrm{O}$ militar coronel Fulgêncio Batista estava aliado aos interesses imperialistas dos EUA, nesta época comandava o exército cubano, posteriormente foi elegido presidente em 1940, sob a égide da constituição que ele mesmo proclamou, mandato que foi até 1944, quando foi para os EUA, regressando somente em 1952, quando em um golpe de Estado, torna-se o ditador.

${ }^{12}$ Segundo Ríos Hernández (2015), o bloqueio imposto pelos Estados Unidos, que inicia praticamente com o início da Revolução, impôs condições que afetavam diretamente a economia do país, tornou impossível "el acceso al mercado de Estados Unidos, asi como efectuar compras em sus subsidiarias en ningún lugar del mundo, lo que limita el acceso a las tecnologias norteamericanas” (RÍOS HERNÁNDEZ, 2015, p. 179). 
alcançou de maneira simultânea o crescimento econômico e a equidade social, por fazer parte do extinto Conselho de Ajuda Mútua Econômica (CAME) ${ }^{13}$, junto ao bloco socialista soviético (MOLINA, 2004, p. 17).

Assim, foi somente após o triunfo da Revolução, em 1959, que a República de Cuba pode começar a formar verdadeiramente um Estado perfeito, com a possibilidade de seu povo se autodeterminar, dentro do território da ilha caribenha, formando seu próprio governo soberano. Inclusive de formar um Estado que se coloca frontalmente contra os interesses do desenvolvimento do modo de produção do capital, cuja concentração de renda e de terras é privativa de uma pequena classe privilegiada, a burguesia. O que obviamente trouxe outros conflitos, e uma luta diária para se manter na escolha da organização de um Estado Socialista, com base na justiça social, igualdade e solidariedade.

Contudo, a formação deste Estado Socialista não se deu de imediato. A primeira preocupação do governo revolucionário era avançar em condições materiais a seu povo, dando-lhes terra, moradia, educação, saúde e alimentação, foi um governo de ações que modificaram a realidade social, econômica e cultural do país. Assim, aqui não havia, ainda, um conceito formado de Estado Socialista, mas ações cujo desencadeamento foi a concepção própria deste conceito. Isto porque, depois da revolução e com o bloqueio econômico imposto pelos EUA, Cuba se aproximou da única possibilidade de relação internacional, o bloco soviético. Contudo, a própria vertente marxista, já se encontrava presente tanto nos escritos de José Martí, herói da primeira guerra de independência, como nos escritos de Ernesto Che Guevara, Fidel Castro e Camilo Cienfuegos, heróis da segunda guerra por independência. Tudo isso foi sendo construído ao longo dos anos, e a prática das ações do governo revolucionário, embasadas nos ideais de uma sociedade mais justa, passam a estar estampadas na Constituição da República de Cuba, promulgada em 1976.

O conceito de Estado Socialista desenvolvido pelos cubanos não é algo fácil de explicar em poucas linhas, mas é necessário pelo menos se delinear algumas características básicas para compreensão. Um primeiro ponto importante é entender que a revolução socialista é um processo em desenvolvimento, como diz Bell Lara, é um "processo social” (1996, p. 25), é a construção das bases materiais que darão condições de sustentar o socialismo. Para isso, é preciso empreender o que Bell Lara chama de "acumulação primitiva

\footnotetext{
${ }^{13}$ O CAME foi, de acordo com Ríos Hernández, o órgão interestatal, integrado pelos países socialistas, ao qual Cuba começou a participar como membro pleno desde 1972, "encargado de conformar y aplicar las medidas de colaboración em todos os aspectos técnicos, económicos, comerciales y de desarrollo técnico y científico, así como los suministros de maquinaria y demás insumos" (RÍOS HERNÁNDEZ, 2015, p. 250).
} 
socialista" (1996, p. 45), compreendida como a distribuição social das riquezas que se gera no país em função do desenvolvimento individual e social, porque os resultados do desenvolvimento econômico estão para os interesses do povo cubano e tem como objetivo chegar a todos os membros da sociedade, segunda característica. Por último, o socialismo deve ser visto, segundo Bell Lara (1996, p. 26), como um modo de vida, incorporando uma série de valores e formas de atuar do povo, como educação para todos, acesso igualitário aos serviços básicos, valores e práticas solidárias (nacional e internacional), e principalmente exige a participação do povo na construção da nova sociedade.

A Professora Yarina Amoroso Fernández respondendo o que é o Estado Socialista cubano disse:

\begin{abstract}
El Estado es para todos. Y se fundamenta en la creencia, la convicción más que grande de que el socialismo es una alternativa de bien estar social, ¿a partir de qué? De una distribución social de las riquezas que se generen en el país en función del desarrollo de la personalidad. Los individuos pueden potenciar al máximo las capacidades individuales, quiero decir que está sustentada en derechos básicos donde todos tenemos las mismas oportunidades. Para hacer a la alimentación, a la vivienda, a los estudios y donde incluso este estado se planifica para garantizar en determinados niveles de la vida del individuo, esto que es el ejercicio de su derecho. Por eso es enseñanza gratuita, todos tenemos las mismas oportunidades (2019).
\end{abstract}

E como Estado para todos exige que todos também contribuam na construção deste Estado, em um exercício de soberania. E no exercício desta soberania, o povo cubano promulgou uma nova Constituição da República (CUBA, 2019), na qual defende seu projeto de Estado Socialista em construção, sustentado pela autodeterminação, decidiu manter o caráter socialista de seu Estado, como exposto no artigo primeiro da nova Constituição (CUBA, 2019):

Cuba es un Estado socialista de derecho y justicia social, democrático, independiente y soberano, organizado con todos y para el bien de todos como república unitaria e indivisible, fundada en el trabajo, la dignidad, el humanismo y la ética de sus ciudadanos para el disfrute de la libertad, la equidad, la igualdad, la solidaridad, el bienestar y la prosperidad individual y colectiva.

Em 10 de abril de 2019, a nova Constituição da República de Cuba foi promulgada, não por acaso nesta data, uma vez que há 120 anos deu-se início à Assembleia de Guáimaro, que conclamava a independência e evocava o povo à luta por sua conquista. Há um significado simbólico de continuidade na escolha desta data, e é para apontar para a continuidade de um projeto de sociedade livre e soberana, e ainda anticolonial. O caráter anticolonial é a característica marcante do constitucionalismo latino-americano, a luta para conquistar a independência e, ademais, é a busca para garantir ao povo e à natureza formas para que possam subsistir. As constituições cubanas, desde 1869 até 2019, são anticoloniais. 
Não pode haver silêncio sobre a promulgação da nova constituição cubana, porque na conjuntura da América Latina ela é um novo marco para refletir o próprio constitucionalismo e a formação dos Estados independentes e anticoloniais do continente. Por isso o enfoque principal deste trabalho é discutir algumas particularidades da nova constituição que caracterizam a continuidade do processo de formação do Estado socialista e, principalmente, daquilo que lhe dá o caráter anticolonial.

A primeira Constituição cubana foi a de 1869, um clamor pela liberdade frente ao julgo de seu colonizador, a Espanha, nas lutas independentistas desde 1968 (CUBA, 2019). Outros textos constitucionais foram aprovados no território ocupado pelos mambises, Baraguá (1878), Jimaguayú (1895) e La Yaya (1897) (SANTANDER, 2018). E a liberdade que só foi conquistada em 1898, mas acabou caindo sob o julgo dos interesses exploradores dos EUA. E sob a pressão deste, promulgou sua segunda constituição em 1901, na qual houve a intervenção estadunidense através da aprovação da Emenda Platt, constituição tipicamente colonial. A terceira veio em 1940, fruto de lutas entre a burguesia crioula e a oposição aliada à classe trabalhadora e camponesa. No ano do triunfo da revolução, entrou em vigência uma Lei Fundamental que derrogava parcialmente a constituição de 1940, mas que a mantinha vigente. Em 1976, foi promulgada a primeira constituição socialista de Cuba, que consolidou o novo paradigma agrário, também criou a propriedade socialista, cujo titular é o povo cubano e traçou diretrizes para o sistema econômico socialista planificado, características que permanecem na nova Constituição de 2019.

Em linhas gerais, a reforma constitucional de 2019 começou por um projeto aprovado na Assembleia Nacional de Poder Popular ${ }^{14}$, e em seguida foi amplamente discutido com a sociedade, em um exercício da soberania popular. Este momento foi composto de várias reuniões com os órgãos de organização popular, principalmente nos municípios. Em todo o país foram mais de 130 mil assembleias, durante os três meses em que ocorreram os debates. Toda a população teve a oportunidade de expressar sua opinião, dizer o que pensava para a construção de sua nação e quase 9 milhões de pessoas participaram da consulta, o que significa que $80 \%$ dos cubanos participou no processo da reforma constitucional, inclusive houve a participação dos emigrantes, foram 760 mudanças à proposta inicial e $60 \%$ dos artigos foram modificados em alguma medida (CUBAINFORMACIÓN, 2019). O projeto foi

\footnotetext{
${ }^{14}$ No sistema político cubano, a Assembleia Nacional de Poder Popular é o órgão máximo do poder legislativo, cujos membros são eleitos pelo voto libre, direto, individual e secreto. E se constitui como o poder constituinte originário ou derivado pela força dos art. 141 da Constituição de 1976 (CUBA, 1976) e, atualmente, pelo art. 226 da Constituição de 2019 (CUBA, 2019).
} 
aprovado na Assembleia Nacional de Poder Popular no dia 22 de dezembro de 2018 e submetido ao referendo popular em 24 de fevereiro de 2019. Também nesta etapa houve grande participação de população (7,8 milhões). Desta, 6,8 milhões votaram sim, a favor da aprovação da nova Carta Magna, o que corresponde ao índice de 86,65\% dos que participaram na votação do referendo.

Deste modo, um dos princípios basilares do Estado Socialista, e mantido na reforma constitucional de 2018-2019, é justamente a participação da população na construção da sociedade. Declara que a soberania emana do povo, que exerce esse poder de forma direta "por medio de las Asambleas del Poder Popular y demás órganos del Estado que de ellas se derivan, en la forma y según las normas fijadas por la Constitución y las leyes", como expresso no artigo $3^{\circ}$ da Nova Constituição da República de Cuba.

Elementos simbólicos de continuidade do processo revolucionário cubano na Nova Constituição, como apontamos anteriormente, foram as datas escolhidas para o referendo e para a promulgação, que representam a continuidade do projeto, demonstrando que não há uma ruptura entre a constituição de 1976 e a de 2019, que se remete à primeira constituição anticolonial de Guáimaro, no século XIX. Como menciona Amoroso Fernández:

\footnotetext{
hay un hilo de continuidad. Incluso pienso que hay un simbolismo real, [inaudible], sino por buscar elementos semióticos, lo que significan los símbolos, los signos en que esto tenga la misma fecha de Guáimaro, que se ha hecho en lo mismo día. Quiero decir, para ayudar al más simple ciudadano a entender de que en esto va un hilo de continuidad en sentido del perfeccionamiento de un documento tan importante como es la constitución (2019).
}

Datas também são apontadas como simbolismo da continuidade pelo atual Presidente da República, Miguel Díaz-Canel Bermudes, em entrevista ao periódico Granma, no dia do referendo, menciona que 24 de fevereiro de 1895 marca a retomada das lutas por independência e, em 1976, a aprovação da Constituição, a primeira concebida dentro do regime socialista (GRANMA, 2019). Para além do simbolismo semiótico que demonstra a continuidade, temos a própria escolha dos cubanos em manter o estado socialista, e o que sempre foi imprescindível nesta formação foi a questão agrária, com distribuição e controle da concentração de terras, por isso, reservamos o tópico seguinte para a discussão deste assunto.

\section{Propriedade da terra e reforma agrária}

Contamos que o período de 1898 a 1959 foi de intensos conflitos devido à condição de miséria que o povo cubano estava sendo submetido com a expropriação e exploração estadunidense, e em toda a ilha, a lo largo y a lo ancho, surgiam lutas obreiras e, 
principalmente, camponesas, como a de Realengo 18. Por isso, a questão agrária se tornou um dos eixos mais importantes não só para a nova luta por Independência, mas também para a formação do Estado socialista cubano. Desta forma, a compreensão da questão agrária hoje, deve decorrer da retomada de todo o contexto da reforma agrária na América Latina e no pós revolução de 1959, especificamente em Cuba.

Mas antes de falarmos sobre a reforma agrária, temos que olhar pelo retrovisor para compreender a transformação da terra em propriedade como um contrato individual, e com vinculação à própria formação do Estado moderno (MARÉS, 2003). Os processos desta transformação foram diferentes nos continentes, na Europa a terra começou a passar pelo processo de cercamento construído através do discurso do melhoramento, cuja noção era o aumento da produtividade visando lucro, para o dono da terra, não para a sociedade, não para os camponeses, que expulsos de suas terras pelo cercamento, passam a depender da compra de alimentos essenciais para sua subsistência, no mercado, onde o dono da terra, que a cercou expulsando o camponês, vende sua mercadoria para obter lucro para si mesmo aumentando seu patrimônio privado (WOOD, 2000). No continente americano, houve a invasão estrangeira vinda do continente europeu, que trouxe toda espécie de atrocidades contra os povos originários, que viviam do que a terra, como natureza, lhes dava, foram expulsos desta terra, muitos foram mortos, pelas armas ou pelas epidemias dos europeus. Segundo Marés (2003, p. 54) "a construção da propriedade privada no Brasil, ou a modernidade, desprezou a ocupação indígena, não respeitou sequer seus mais elementares direitos, como os de sobrevivência”. Este processo não foi diferente na ilha cubana, os espanhóis colonizadores, ao chegarem à ilha, expropriaram os indígenas de suas terras, escravizando-os e, posteriormente, extinguindo-os, como relata Ríos Hernández (2015, p. 13).

E o Estado moderno capitalista passou a ter a função de defender essa propriedade privada e excludente, leis foram criadas para naturalizar o direito absoluto de uma única pessoa a um pedaço de terra, que se expande cada vez mais para aumentar o lucro do dono da terra. E "embora não esteja dito, está claro que a Constituição e as leis que a regulamentam tratam a terra como bem jurídico, objeto do direito absoluto e excludente" (MARÉS, 2003, p. 39). E será justamente nesta lógica que a reforma cubana altera a estrutura agrária para a construção de um Estado com base na acumulação socialista, não individual e não excludente, não para lucro de uma única pessoa. 
A reforma agrária foi posta em pauta, principalmente após as décadas de 1950-1960, em muitos países da América Latina e Caribe ${ }^{15}$. Reformas que assumiram diversos vieses e matizes, como Carmen Cohene Mercado (2018) relata no capitulo III de sua tese sobre reforma agrária no Paraguai, algumas impulsionadas pelo Estado, outras por um contra poder como movimentos sociais. As impulsionadas pelos Estados, umas foram com o objetivo de redistribuição da terra, outras somente como forma de avanço da agricultura industrial ${ }^{16}$. No caso de Cuba, foi uma reforma agrária com intensão de redistribuição de terras feita pelo Estado, e exemplo para outros povos,

desafió el sistema haciendatario y repercutió en la mayoría de los países de la región, de manera directa en Centroamérica e indirecta más al sur del continente ante la amenaza del socialismo, y la posibilidad que "la revolución" se expandiera a otros países de la región. (COHENE MERCADO, 2018, p. 214)

A história da reforma agraria em Cuba está relacionada diretamente com o triunfo da revolução em $1^{\text {o }}$ de janeiro de 1959, momento em que se estabeleceu o governo revolucionário e uma nova ordem jurídico institucional. Como nos referimos anteriormente, o período neocolonial trouxe o desenvolvimento na base capitalista, ou seja, com concentração de renda e desigualdades sociais. Em 1959, somente 1,5\% dos proprietários de terras possuíam mais de 46\% da área nacional em fazendas privadas (RÍOS HERNÁNDEZ, 2015, p. $161)$.

Em fevereiro do ano do triunfo da revolução, foi promulgada a Ley Fundamental $^{17}$, cujas diretrizes foram marcadas por rupturas e continuidades em relação à Constituição de 1940 (CARRERAS, s/d, p. 507). Uma das continuidades foi a manutenção do art. 91, que obrigava o poder público a controlar a acumulação de propriedade privada, norma que nunca havia sido cumprida, mas que criou a legitimação para a Primeira Lei de Reforma Agrária, em 17 de maio, a qual se refere expressamente (CARRERAS, s/d, p. 511). Obviamente, este artigo se encontrava na Constituição de 1940 devido a uma disputa dos delegados comunistas ante os mais conservadores, como relata Ríos Hernández (2015, p. 159):

\footnotetext{
${ }^{15}$ Sobre reformas agrárias na América Latina se pode aprofundar com a leitura da tese de doutoramento de Carmen Cohene Mercado (2018), que trata da reforma agrária no Paraguai, mas no capitulo 3, faz uma análise de outros países latino-americanos.

${ }^{16}$ Um bom exemplo é a reforma agrária no Brasil, cujo Estatuto da Terra (Lei no 4.504 de 64), lei que regula a reforma agrária, traça suas principais linhas de fundamento, a qual expressamente não é a redistribuição de terras, mas a proteção à propriedade privada, desenvolvimento econômico e industrialização do campo. Contudo, a necessidade de redistribuição permanece latente e fez nascer um movimento, o Movimento dos Trabalhadores Rurais Sem Terra (MST), que reivindica do Estado ações em direção à redistribuição da terra, para que cumpra sua função social.

${ }^{17}$ Além da Lei Fundamental, houve, como processo de construção da formação do Estado Socialista Cubano, duas Assembleias Gerais Nacionais do Povo Cubano, realizadas na Praça da Revolução José Marti, na capital Havana, nas quais foram aprovadas a $1^{\mathrm{a}}$ e a $2^{\mathrm{a}}$ Declaração de Havana (FERRALS, 2018).
} 
La Reforma Agraria, soñada por los campesinos y algunos hombres de ideas progresistas en la república neocolonial, introducida casi a la fuerza en la Constitución de 1940 por los delegados comunistas, pero nunca aplicada, y proclamada como uno de los objetivos revolucionarios en el Programa del Moncada, sólo pudo ser aplicada con el triunfo revolucionario del primero de enero de 1959.

Desta forma, a primeira lei, teve o objetivo de limitar o máximo de extensão de terra que uma pessoa natural ou jurídica poderia possuir (RÍOS HERNÁNDEZ, 2015, p. 160). Depois disso, se criaram mecanismos de desapropriação das terras que excediam os limites legais, como a Segunda Lei de Reforma Agrária, promulgada aos 03 de outubro de 1963, que teve a finalidade de estabelecer limite máximo de 67 hectares às propriedades privadas da terra, e nacionalizar as que estavam acima deste limite (RÍOS HERNÁNDEZ, 2015, p. 172).

Importante mencionar que todas as desapropriações, desde a primeira lei de reforma agrária, foram realizadas de forma legalizada e estabelecia uma indenização, como se observa no artigo 29, da Primeira Lei de Reforma Agrária (CARRERAS, s/d). O caráter de direito absoluto da propriedade foi mantido nestas desapropriações, tendo em vista que houve uma compensação financeira que recompôs aos sujeitos proprietários que sofreram a desapropriação seu patrimônio individual, ou seja, o direito de propriedade não foi desconstituído. Como aponta Marés (2003, p. 65),

A partir da Constituição dos Estados e ainda persiste na mentalidade de muitos juristas do século XXI, nem o Estado nem a sociedade podem desconstituir a propriedade de alguém sem lhe dar outra propriedade, em substituição, recompondo integralmente o seu patrimônio individual. Essa nova propriedade dada em troca, em geral é dinheiro e o instituto de transferência se chama desapropriação.

Essas terras tiveram duas destinações. A primeira cumpriu a função de manter o camponês em suas terras, legalizando como propriedade os arrendamentos e com a entrega de terras, de forma gratuita, a 1.000 famílias de camponeses. As outras terras, que não tiveram destinação privada, foram nacionalizadas e transformadas em propriedade socialista ${ }^{18}$. Como o autor Arturo Soto Piper aponta, a nacionalização das propriedades foi um "acto de

\footnotetext{
${ }^{18}$ Atualmente, os EUA têm ameaçado estas propriedades nacionalizadas com a aplicação do Título III, da Lei Helms-Burton, cujos efeitos vinham sendo suspensos, mas em janeiro de 2019, o governo de Trump eliminou essa suspensão. Esta lei é um desrespeito à soberania cubana, em razão da utilização de uma lei criada no território dos EUA, que portanto, pelo princípio da territorialidade, só pode ter efeitos em seu próprio território, que é a Lei Helms-Burton, assim chamada justamente por levar o nome os legisladores estadunidenses. Desde o triunfo da revolução, os EUA mantém um bloqueio unilateral contra Cuba, que veio sendo construído de variadas formas, uma destas tentativas de sistematizar legalmente este bloqueio foi através de legislação nacional, como a Lei Torricelli de 1992 e a Lei Helms-Burton de 1996. Ocorre que esta última, no Título III, refere-se à possibilidade dos americanos e dos cubanos naturalizados americanos de questionarem no judiciário norte-americano e reivindicarem suas propriedades privadas, abandonadas ou legalmente desapropriadas e nacionalizadas, desde o ano de 1960 . No entanto, estes institutos jurídicos ferem flagrantemente, o princípio da soberania dos estados modernos, impondo sanções que não só extrapolam a jurisdição dos EUA, mas também trazem insegurança jurídica por alcançarem fatos pretéritos, devido ao seu caráter retroativo, cuja desapropriação ocorreu de forma legalizada, dentro dos interesses nacionais (SOTO PIPPER, 2008).
} 
reivindicación económica, por causa de utilidad pública o interés social o nacional, de beneficio popular y sí lleva aparejada compensación - como establece la Constitución -, una apropiada indemnización (SOTO PIPPER, 2008, p. 19)". Assim, as terras que não tiveram destinação aos camponeses, foram formando a propriedade socialista (CUBA, 1976; CUBA, 2019), cujo titular do direito é o povo cubano e sua gestão é realizada pelo Estado, em nome e em benefício do povo. Esta gestão foi realizada pelo Estado em diversas áreas da economia, no setor agrícola com a criação das Fincas Estatales.

Assim, a economia foi adaptada à forma planificada de economia de Estado, com forte presença nas atividades econômicas, inclusive no setor agrícola. De tal modo, foram constituídas empresas estatais para o desenvolvimento da produção no campo. Esse desenvolvimento agrícola foi baseado na modernização das técnicas da "Revolução verde", isto em toda a região da América Latina e Caribe, e vinculado aos processos de reforma agrária na região (COHENE MERCADO, 2018, p. 92). Em Cuba não foi diferente, no período de 1960 até o fim da União Soviética, o desenvolvimento agrícola foi baseado nas técnicas e insumos advindos da agricultura industrial. E dentro deste sistema de produção, baseado em monocultivo para exportação, criou uma dependência das importações de alimentos, para a efetivação do direito humano à alimentação. Como todas as relações comerciais eram com o bloco socialista soviético, quando se extingue, entram no que ficou conhecido como período especial, no qual o primeiro efeito foi a impossibilidade de importações, inclusive de gêneros alimentícios, foi então, que necessitou reaprender e resgatar os conhecimentos tradicionais para plantar comida e reorganizar a distribuição de terras (MACHÍN SOSA et.al., 2013).

Embora o processo de reforma agrária estivesse atrelado à mecanização e utilização da agricultura industrial e, ainda, que um dos efeitos das desapropriações tenha sido a acumulação da propriedade pública e tutelada pelo Estado, isto foi de fundamental importância para o processo de recuperação do período especial. Neste período houve uma mobilização do povo e com as políticas governo para a formação de um novo modelo de agricultura foi chamado de revolução agroecológica (MACHÍN SOSA et.al., 2013). Uma das políticas do Estado foi a redistribuição das terras em usufruto aos agricultores, que ocorre tanto individualmente, como coletivamente.

Individualmente foram distribuídas terras, urbanas e rurais, a quem tivesse interesse em plantar, segundo dados de Díaz (2014, p. 163), foram distribuídos em usufruto, mais de 1 milhão de hectares de terras que estavam ociosas: 
- distribución en usufructo de 1 millón 367 mil hectáreas de tierras que permanecían ociosas a 171.235 personas, con significativos impactos en la producción alimentaria.

- Más de 8 mil hectáreas de organopónicos y huertos intensivos de la Agricultura urbana en todas las ciudades y pueblos del país, en los cuales trabajan unas 350 mil personas; se produjeron en 20121 millón 51 mil 918 toneladas de hortalizas y ha habido una significativa contribución a la biodiversidad en especies y variedades de hortalizas y de frutales.

- Más de 260 mil hectáreas de fincas entregadas igualmente en usufructo en la Agricultura suburbana, que atienden unos 185 mil productores.

A redistribuição de terras de forma coletiva se deu através da criação das Unidades Básicas de Produção Cooperativada (UBPC), após a queda do bloco socialista soviético surgiu a necessidade de transformação das relações de produção para possibilitar o desenvolvimento das forças produtivas no campo, assim, houve a destinação das terras, onde estavam instaladas as empresas estatais para os trabalhadores agrícolas, organizados de forma cooperada, em usufruto por tempo indefinido, situação que foi regulamentada, inicialmente, pelo decreto lei $n^{\circ} 142 / 93$ (GONZÁLEZ, 2002, p.03) e posteriormente pelos Decreto-lei $n^{\circ}$ 259/08 e Decreto-lei n ${ }^{0}$ 300/12. Assim, o uso das terras, de propriedade socialista, é entregue de forma gratuita ${ }^{19}$ aos trabalhadores, que coletivamente assumem a gestão e passam a produzir alimentos necessário para a superação do período especial e para garantir segurança alimentar ao povo.

Buscou-se, assim, a descentralização e redemocratização do uso da terra. Díaz (2014, p. 163) aponta que os resultados da pesquisa "muestran un proceso de descentralización hacia lo local y democratización en la gestión de la tierra, aun cuando no se ha distribuido su propiedad, considerada patrimonio de la nación y permanece bajo custodia estatal". Neste sentido, devemos observar que foi utilizado o instituto jurídico de usufruto, no qual o uso da terra é cedido gratuitamente ao agricultor, individual ou coletivo, sem transferir a titularidade do proprietário que, no caso, continua sendo o povo cubano.

É perceptível, portanto, que o Estado Socialista cubano reconheceu o direito à propriedade privada desde o início de sua formação. Neste sentido, torna-se importante elidir uma possível confusão de algum leitor da nova Constituição cubana ao se deparar com uma norma que reconhece a propriedade privada, e que não havia dispositivo normativo precedente na Constituição anterior. O artigo 22, da nova Constituição (CUBA, 2019), que trata das formas de propriedade, inseriu a alínea "d", na qual reconhece a privada. Para

\footnotetext{
${ }^{19}$ Segundo González (2002, p.04), o uso da terra foi cedido a título gratuito, no entanto, em relação às benfeitorias das empresas estatais, os meios de produção foram transferidos a propriedade, assim os trabalhadores cooperados se tornaram "proprietários dos demais meios de produção, os quais devem amortizar em período determinado observado juros baixos e um prazo de mora".
} 
elucidar, foi perguntado para Amoroso Fernández se sempre houve o reconhecimento da propriedade privada em Cuba e, se sim, porquê reconhece-la constitucionalmente agora, a que respondeu:

Siempre hubo... es porque no lo estaba dicho y hay quien quiera que el recogido no afectaba para nada el reconocimiento explícito y al mismo tiempo hay una proyección de relaciones económicas diferentes, digamos, algunos elementos introducen también una garantía de inversores. (AMOROSO FERNÁNDEZ, 2019)

Assim, esse reconhecimento do direito à propriedade privada está relacionada com as questões de desenvolvimento econômico, com a busca de novos investidores estrangeiros, como forma de explicitar garantias e proteção às relações econômicas internacionais. Este reconhecimento não tem o objetivo de alterar a estrutura agrária no país, nem mesmo o caráter socialista do Estado, posto que a propriedade socialista é trazida para a nova Constituição (CUBA, 2019, art. 22, alínea "a"). Além disso, a propriedade privada sobre a terra continua a ser regulamentada pelo sistema jurídico cubano, como prevê os art. 29 e 30 (CUBA, 2019), no qual se proíbe arrendamento, empréstimos hipotecários, compra e venda permanece regulada pelo Estado, bem como o controle da concentração de terras, impondo limites às áreas e, principalmente, a redistribuição realizada pelo usufruto.

Com isso, a Constituição de 2019 recepcionou a legislação construída nestes 60 anos do processo revolucionário. Pode-se dizer, então, que a questão agrária é um aspecto de continuidade e de avanço no sentido da formação do Estado cubano, livre, soberano, independente e, sobretudo, socialista. Apoiado pela reforma agrária iniciada no ano de 1959, enfrentou o sistema latifundiário vigente, distribuiu terras aos camponeses, impediu a concentração, para garantir ao povo cubano justiça social.

A Constituição cubana de 2019 foi, assim, promulgada para que o Estado e a Sociedade de Cuba pudessem se adequar aos novos desafios que de resto já estavam sendo enfrentados. Aqui há uma diferença grande entre esta Constituição cubana e outras constituições do constitucionalismo anticolonial latino-americano: enquanto a maior parte das Constituições projetam mudanças ou garantem direitos que favoreçam ou indiquem mudanças anticoloniais, esta Constituição consolida as mudanças havidas. Tomando o próprio exemplo de Cuba, a Constituição de 1940 abriu a possibilidade de reduzir ou regulamentar a propriedade abusiva da terra, mas era apenas uma promessa que somente pode ser legislada depois da Revolução de 59. Esta Constituição de 2019 em seu artigo acerca da propriedade da terra consolida a experiência agroecológica já em prática há muitos anos, o que significa que a luta dos camponeses será não para por em marcha a Constituição, mas para não permitir o seu rompimento. 


\section{Considerações finais}

Este artigo procurou trazer a discussão sobre a mais nova constituição do continente, fundada no constitucionalismo latino-americano anticolonial. No momento histórico em que se vive na América Latina é muito importante discutir Cuba e seu futuro, assim como os ensinamentos da agricultura agroecológica que está em curso alimentando o país.

No decorrer destas linhas, tratamos da questão agrária como ponto fundamental para a formação e o desenvolvimento do Estado socialista cubano, e verificamos a extrema importância desta questão para a continuidade do conceito de socialismo em Cuba. Ou seja, é a espinha dorsal que não pode ou não se deve alterar, sua mudança acarretaria riscos de danos à estrutura.

Obviamente, houve mudanças no sistema econômico, social e jurídico com a nova Constituição, que foram necessárias para que a ilha no Caribe pudesse se adequar para sobreviver e manter seus ideais de equidade e justiça social, aos novos tempos de globalização, estas mudanças ficam para serem estudadas em uma outra oportunidade.

Portanto, a reforma constitucional foi importante e necessária para se ajustar a determinada forma de realização econômica e, sobretudo, realização econômica para sustentar o desenvolvimento social (AMOROSO FERNÁNDEZ, 2019). Foi necessário mudar para se adaptar aos novos tempos, como diz Tony Ávila (2018), um cantautor cubano, na música chamada "Mi casa.cu", aponta para a necessidade de mudanças, "aprende con el tempo que se puede cambiar que se dañe la estrutura", adiante diz "hay cambios que mi casa necesita", mudará a cor das paredes, os móveis, alterará algumas paredes, mas “al cabo esta será la misma casa, lo que no son iguales son los tiempos". Esta música é uma alegoria da sociedade cubana na atualidade, isto fica muito claro no vídeo oficial, que mostra uma casa sendo alterada por várias mãos, de todas as cores, idades e sexo, ao fundo uma bandeira cubana também é montada ao mesmo tempo em que as mudanças da casa vão ocorrendo, para indicar a analogia entre casa e sociedade. É possível interpretar que Cuba está sendo construída, que algumas mudanças foram necessárias, outras estão por vir, mas os princípios e fundamentos da sociedade continuarão os mesmos, e estão expressos na antiga e na nova Constituição da República de Cuba. Constituições fortemente latino-americanas por seu caráter anticolonial em defesa da sociedade humana e da natureza. 


\section{Referências}

AMOROSO FERNÁNDEZ, Yarina. ¿Vamos hablar de la Reforma Constitucional de Cuba? Entrevista concedida à autora, em abr. 2019.

ÁVILA, Tony. Mi casa.cu. Diretor Alfredo Ureta. Youtube. Publicado em 06 set. 2018. Disponível em: https://www.youtube.com/watch?v=gdr5egQOcUY. Acesso em: 04 jul. 2019.

BELL LARA, José. Los cambios mundiales y las perspectivas de la Revolución cubana. In: BELL LARA, José; PULIDO ESCADELL, Clara. Visón desde Cuba. Editoria Sod\&Paz, Madrid-ES, 1996, p. 7 a 108.

CARRERAS, Julio A. Historia del Estado y del Derecho em Cuba. s/d.

CASAS, Frei Bartolomé de Las. Brevissima relação da destruição das índias. O paraíso perdido. $4^{\mathrm{a}}$ Ed. Porto Alegre: L\&PM, 1985.

CUBA. Constitución de la República de Cuba. Promulgada em: 10 abr. 2019. Online. Disponível

em: http://www.granma.cu/file/pdf/gaceta/Nueva\%20Constituci\%C3\%B3n\%20240\%20KB-1.pdf . Acesso em 07 jul. 2019.

CUBA. Constitución de la República de Cuba. Promulgada em 24 fev. 1976. Online. Disponível em: https://archivos.juridicas.unam.mx/www/bjv/libros/6/2525/52.pdf. Acesso em 07 jul. 2019.

CUBAINFORMACIÓN. Cuba: la diferencia entre dictadura y democracia. Online. Youtube. Publicado em 21 jan. 2019.Disponível em: https://www.youtube.com/watch? $v=$ VFXWTGLZRIg\&list $=$ WL\&index $=67 \& \mathrm{t}=0 \mathrm{~s} \quad$. Acesso em 07 jul. 2019.

DALlARI, Dalmo de Abreu. Elementos de Teoria Geral do Estado. 29. ed. São Paulo: Saraiva, 2011.

DÍAZ, Beatriz F. Agricultura y soberanía alimentaria en un contexto de cambio climático. La transformación agroecológica de Cuba. In: DELGADO RAMOS, Gian Carlo; CORNETTA, Andrei; DÍAZ, Beatriz F. Cambio Climático global, transformación agraria y soberanía alimentaria en América Latina - 1a ed. - Ciudad Autónoma de Buenos Aires: CLACSO, 2014. 
FERNANDES, Florestan. Da guerrilha ao socialismo: a revolução cubana. $3^{\mathrm{a}}$ ed. São Paulo: Expressão Popular, 2012.

FERRALS, Matha Goméz. Primera Declaración de La Habana: los principios de Cuba. Publicado em 02 set, 2018. Diponível em: http://www.adelante.cu/index.php/es/historiaincio/sucesos-submenu/14521-primera-declaracion-de-la-habana-los-principios-de-cuba. Acessado em 01 nov. 2019.

GRANMA. 24 de fevereiro: dia de continuidade, reafirmação e união. Publicado em fev. de 2019. Disponível em: http://pt.granma.cu/cuba/2019-02-28/24-de-fevereiro-dia-decontinuidade-reafirmacao-e-uniao. Acesso em jul. de 2019.

GONZÁLES, Armando Nova. As Unidades Básicas de Produção Cooperativada e as Granjas Canavieiras em Cuba - 1993-2000. Tradução de Candido Vieitez. In: Revista ORG \& DEMO, 1/.3, p.3-I8, 2002. Disponível em: http://www2.marilia.unesp.br/revistas/index.php/orgdemo/article/view/437. Acesso em jul. de 2019.

GUERRA VILABOY, Sergio. Cuba: uma história, México: Ocean Sur, 2012. 220 p.

LEAL SPENGLER, Eusébio. Regresar en el tiempo. La Habana: Publicaciones Imago, 1995.

MACHÍN SOSA, B.; ROQUE JAIME, A.M.; LOZANO, D.R.A.; ROSSET, P.M. Revolução agroecológica: o movimento de camponês a camponês da ANAP em Cuba. $2^{\mathrm{a}}$ ed. São Paulo: Expressão Popular, 2013.

MALUF. Sahid. Teoria geral do Estado. $26^{\mathrm{a}}$ ed., rev. e atual. Miguel Alfredo Malufe Neto. São Paulo: Saraiva, 2003.

MARÉS, Carlos Frederico. A função social da terra. Porto Alegre: Sergio Antônio Fabris Editor, 2003.

MARTÍ, José. Páginas escogidas. Selección y prologo de Roberto Fernández Retamar. 2 tomos. Habana: Instituto Cubano del Libro. 1971. 750 p.

RICHARDSON, R. J. Pesquisa social: métodos e técnicas. São Paulo: Atlas, 1985.

RÍOS HERNÁNDEZ, Arcádio. La agricultura en Cuba. La Habana (Cuba): Editorial INFOIIMA, 2015. 
SANTANDER. José Luiz Toledo. As constituições cubanas, desde ontem até hoje. Publicado em 19 jul. 2018. Disponível em: http://pt.granma.cu/cuba/2018-07-19/asconstituicoes-cubanas-desde-ontem-ate-hoje. Acesso em 01 nov. 2019.

SOTO PIPPER, Arturo. La Ley Helms-Burton y el Derecho Internacional. Tese (doutorado em ciências jurídicas). 162 fls. Universidade de Oriente Faculdade de Direito: Santiago de Cuba, Cuba, 2008. SUARÉZ, Raúl Quintana. Los componentes ético-políticos en la ideología de la Revolución Cubana: fortalezas y debilidades. Edição: Fundación Universitaria Andaluza Inca Garcilaso, 2013. Disponível em: http://www.eumed.net/librosgratis/2013a/1307/index.htm. Acesso em: 11 jul 2019.

WOOD, Ellen Meiksins. As origens agrárias do capitalismo. Revista Crítica Marxista, n. 10, ano 2000. São Paulo: Boitempo, p. 12-30. 